Vol. 11 (3): 585-592 (2021)

\title{
ALUMINUM PHOSPHIDE POISONING: CASE SERIES
}

\author{
Esmeralda Thoma ${ }^{1 *}$, Klotilda Vrenjo ${ }^{2}$, Sonila Bitri ${ }^{3}$ \\ $I^{*}$ University Hospital “Mother Teresa”, Service of clinical toxicology and addictology, Tirana, Albania; \\ ${ }^{2}$ University of Sports, Tirana, Albania; \\ ${ }^{3}$ American Hospital 2, Tirana, Albania;
}

Corresponding Author Esmeralda Thoma, e-mail: esmeraldahoxha@yahoo.com;

Received March 2021; Accepted April 2021; Published June 2021;

DOI: https://doi.org/10.31407/ijees11.330

\begin{abstract}
Aluminum phosphide (AIP) is an agent mostly used for it`s pesticide properties. It is the major cause of suicide poisoning associated with high mortality in Albania. As soon as AlP is exposed to a moisture environment it undergoes a reaction producing phosphine, a gas which is lethal. It inhibits cytochrome $\mathrm{C}$ oxidase and then it causes cell hypoxia due to the inhibition of oxidative phosphorylation. The signs and symptoms are not specific, even though nausea, vomiting, abdominal cramps and hypotension are almost always present. The diagnosis is made mainly by clinical history of the patient and clinical presentation. AlP poisoning has no antidote, and the treatment is mainly focused on symptom management, and supportive measures. This article, represents three cases of aluminium phosphide poisoning, two young girls and one young man. All of them were hospitalized due to the diagnosis of Aluminum phosphide poisoning. The diagnosis was made from clinical presentation of the patients and medical history taken mostly from them and their relatives. Two of the patients presented with abdominal pain, nausea, vomiting with characteristic garlic odor, hypotension, cyanosis, and severe metabolic acidosis. Both survived. The other one, a young girl, was taken to hospital by her friends. She was conscious, cooperative with mild and nonspecific symptoms on arrival. On the fifth day she died.

Conclusion: There is still a lot to know about pathological mechanisms of AlP poisoning, the best treatment that can be offered to a specific patient and the right time when it should be applied.
\end{abstract}

Key words: aluminum phosphide, poisoning, phosphine, hypotension. 